\title{
Correction to "Do we have the guts to go? The abdominal compartment, intra-abdominal hypertension, the human microbiome and exploration class space missions"
}

$T$ here were errors in the author list of the article "Do we have the guts to go? The abdominal compartment, intra-abdominal hypertension, the human microbiome and exploration class space missions" by Kirkpatrick and colleagues, ${ }^{1}$ published in the November-December issue. Some names were misspelled and degrees incorrect.

We apologize for the error. The article has been corrected at canjsurg.ca.

DOI: $10.1503 /$ cjs. 024120

\section{Reference}

1. Kirkpatrick AW, Hamilton DR, McKee JL, et al. Do we have the guts to go? The abdominal compartment, intra-abdominal hypertension, the human microbiome and exploration class space missions. Can 7 Surg 2020;63:E581-93. 